\title{
Post Circumcision Penile Epidermal Inclusion Cyst: A Case Report
}

\author{
Ofoha C.G., Dakum N.K. \\ Division Of Urology, Department of Surgery, Jos University Teaching Hospital, P.M.B 2076, Jos, Nigeria.
}

\begin{abstract}
Post circumcision penile epidermal inclusion cysts are rare and few cases have been reported worldwide. A five year old boy presented with a complaint of a mass located at the dorsal aspect of the penis along the circumcision scar. The mass was noticed few weeks after circumcision. On examination the mass was located at the dorsal aspect of the penis proximal to the coronal sulcus along the circumcision scar and measured about $1 \mathrm{~cm} \times 1.5 \mathrm{~cm}$. It was oval in shape with no differential warmth and non tender. The mass was smooth, firm, mobile and with well defined edges. The overlying skin was normal with no punctum. The mass was excised under general anaesthesia. Histologic sections show an attenuated cystic structure, lined by stratified squamous epithelium containing keratin debris and amorphous material. Histologic diagnosis was epidermal inclusion cyst. Post circumcision epidermal inclusion cyst is usually easy to diagnose from history and physical examination. Complete total excision is usually curative and prevents recurrence.
\end{abstract}

Key words: Post Circumcision; Epidermal Inclusion Cyst; Penis

\section{Introduction.}

Epidermal inclusion cysts are benign lesions that can develop in any part of the body. However, the finding of an epidermal inclusion cyst in the penis is rare [1].

Few cases of post circumcision penile epidermal inclusioncyst have been reported [2],[3].

\section{Case report}

A five year old boy presented at the urology outpatient with a chief complaint of a mass located at the dorsal aspect of the penis along the circumcision scar. The mass was noticed few weeks after circumcision which he had at seven days of age and had progressively increased in size. He had occasional dull pain which was not severe enough to restrict his activities. He had no history of penile trauma except the circumcision, inflammation, lower urinary tract symptoms or urinary tract infection. However, there was significant parental anxiety. On examination the mass was located at the dorsal aspect of the penis proximal to the coronal sulcus along the circumcision scar and measured about $1 \mathrm{~cm} \times 1.5 \mathrm{~cm}$. It was oval in shape with no differential warmth and non tender. The mass was smooth, firm, mobile and with well defined edges. The overlying skin was normal with no punctum. No swelling was noticed in other parts of the body and there was no regional lymphadenopathy.

The mass was excised under general anaesthesia.

Macroscopically, the cut surface of the mass was full of a cheese-like material. Histologic sections showed an attenuated cystic structure, lined by stratified squamous epithelium containing keratin debris and amorphous material.Histologic diagnosis was epidermal inclusion cyst.

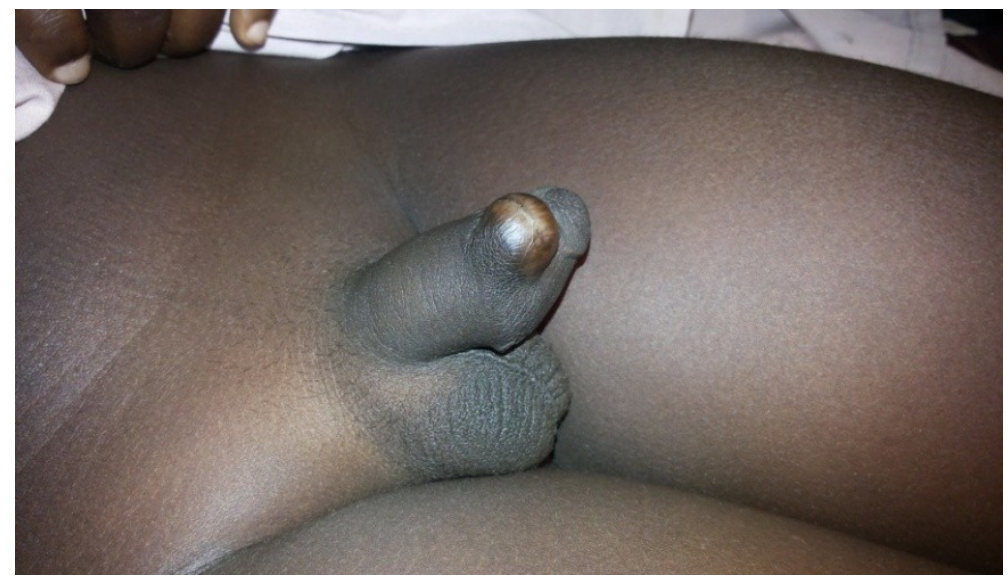

Figure1: Firm mass at the dorsal aspect of the penis. 


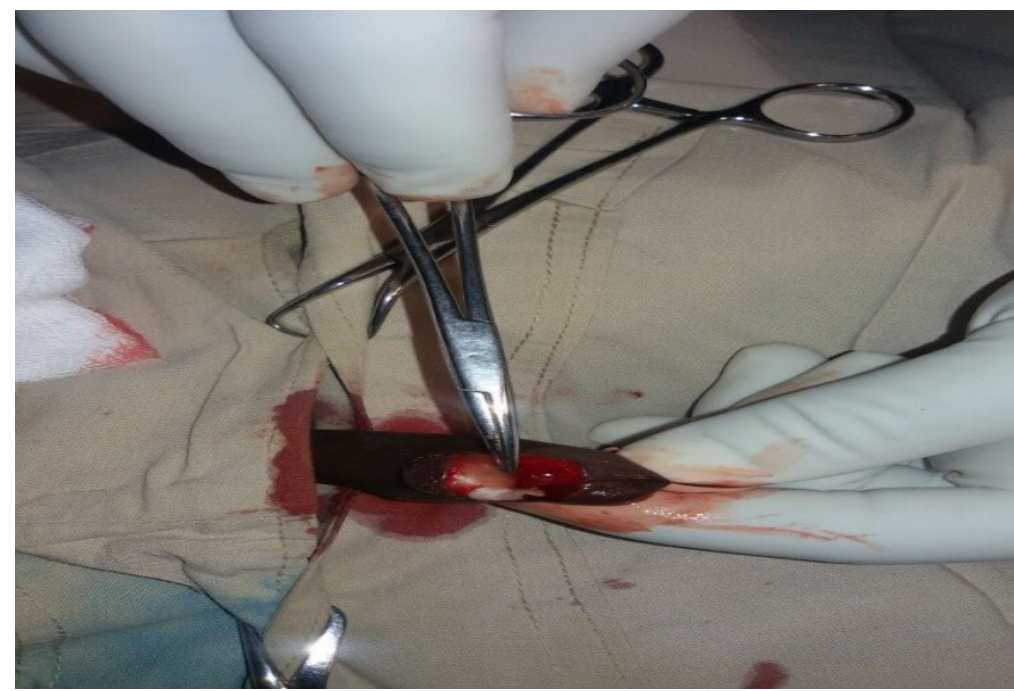

Figure 2: Intra op dissection of the mass

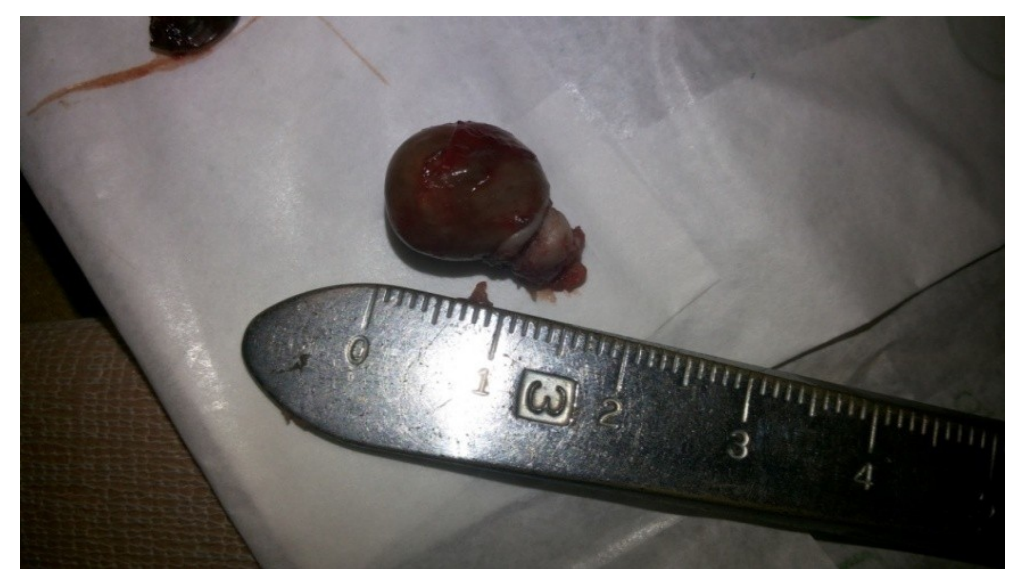

Figure 3: Excised mass
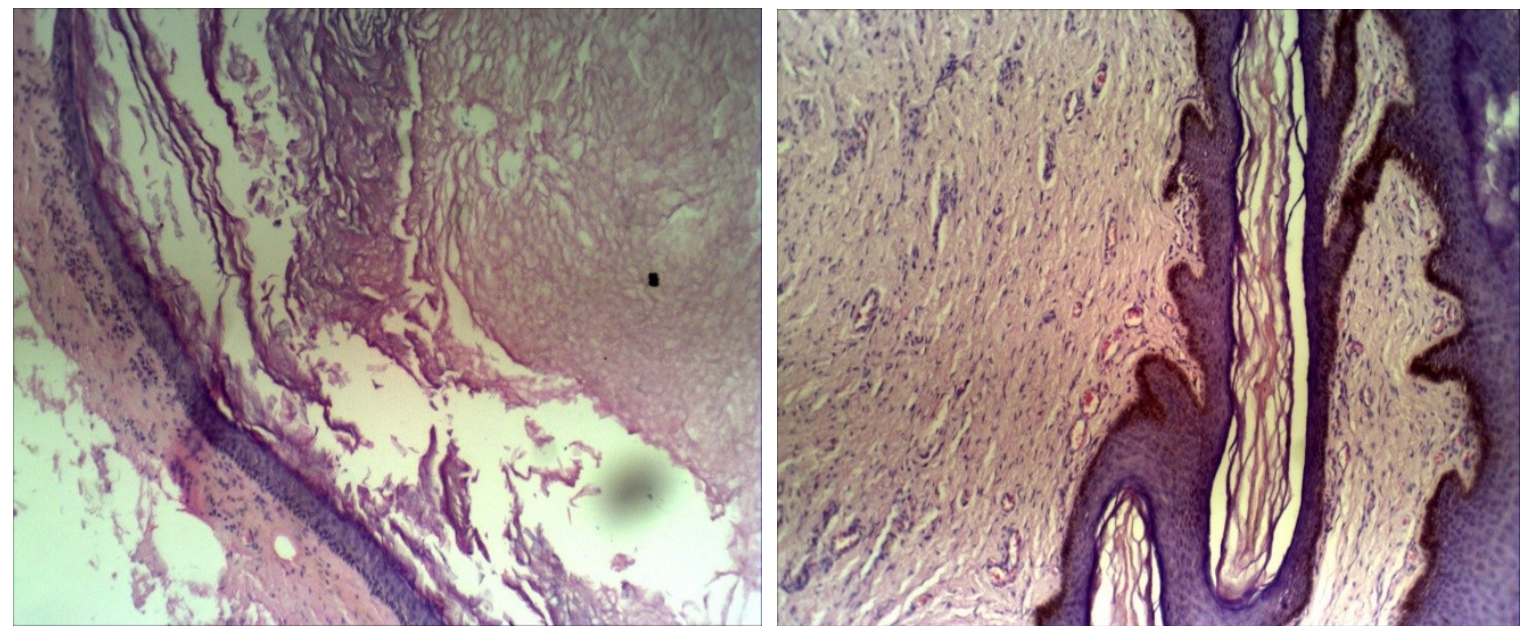

Figure 4: Histologic section of the excised mass

\section{Discussion}

Historically, epidermoid cysts have been referred to by various terms, including follicular infundibular cysts, epidermal cysts, and epidermal inclusion cysts. The term epidermal inclusion cyst refers specifically to an epidermoid cyst that is the result of the implantation of epidermal elements in the dermis.

Histologically, they are lined by well-developed stratified epithelium without a skin appendage, and are composed of keratin-producing epithelium [4],[5]. 
Khanna et al[6] proposed the criteria for a penile epidermoid cyst, the cyst should be surrounded by penile tissue, filled with keratin only, lined with surrounding fibrous connective tissue and with an inner lining of stratified squamous epitheliumand without dermal appendages.

Epidermal inclusion cysts may result from traumatic implantation of epidermal tissue into the dermis or the subcutaneous tissue. The implanted tissue may become cystic and filled with laminated keratin, cholesterol crystals, and debris. These cysts usually remain asymptomatic unless they become infected, grow large enough to interfere with normal function, or rupture into the adjacent soft tissues. If the cyst wall ruptures, a secondary foreign body-type granulomatous reaction or an abscess may develop [7].

In the index case, it is possible that epidermal elements were implanted into the subcutaneous tissue during circumcision. Though the mass remained mostly asymptomatic, there were periods when the child experienced dull pain which can be attributed to the pressure effect of the mass as there were no features suggestive of inflammation, rupture or infection.

Epidermal inclusion cysts may also result from the sequestration of epidermal rests during embryonic life, occlusion of the pilosebaceous unit, or traumatic or surgical implantation of epithelial elements. Human papilloma virus infection, ultraviolet exposure, and eccrine duct occlusion may be additional factors [8].

Simple complete excision has been regarded as the best treatment procedure for penile epidermal inclusion cysts [4],[5]. If the entire cyst wall is not removed, the lesion may recur.In this case the cyst was completely excised.Rupture of the cyst wall can lead to a severe inflammatory reaction that is extremely painful, and definitive treatment requires surgical excision of the entire cyst wall to prevent cyst recurrence [9]. Aspiration or simple drainagecarries risk of recurrence.

Neoplastictransformation of the epitheliumof epidermal inclusion cysts has been reported rarely but not in penilecases [10].

\section{Conclusion}

Post circumcision epidermal inclusion cyst is extremely rare. It is usually easy to diagnose from history and physical examination. Complete total excision is usually curative and prevents recurrence.

\section{REFERENCE}

[1]. Park HJ, Park NC, Park SW, Jern TK, Choi K-U. Penile epidermal inclusion cyst: A late complication of penile girth enhancement surgery. J Sex Med. 2008;5(9): 2238 - 2240.

[2]. Okeke LI. Epidermal inclusion cyst as a rare complication of neonatal male circumcision: a case report. Journal of Medical Case Reports.2009; 3:7321.

[3]. Ademuyiwa AO, Ojewola RW, Elebute OA, Jeje EA, Bode CO. Surgically Correctable Morbidity from MaleCircumcision: Indications for Specialist Surgical Care in Lagos: Nigerian Journal of Surgery. 2012;18(2): 71-74.

[4]. Suwa M, Takeda M, Bilim V and Takahashi K.Epidermoid Cyst of the Penis: A Case Report and Review of the Literature.International Journal of Urology.2000; 7 (11):431-433.

[5]. Rattan J, Rattan S, GuptaDK.Epidermoid Cyst of the Penis with Extention into the Pelvis.The Journal of Urology. 1997; 158(2): p. 593.

[6]. Khanna S. Epidermoid Cyst of the Glans Penis.European Urology.1991;19(2):176-177.

[7]. Cho JH, Chang JC, Park BH, Lee JG, Son CH. Sonographic and MR imaging findings of testicular epidermoid cysts. AJR.2002; 178(3):743-748

[8]. Egawa K, Kitasato H, Ono T. A palmar epidermoid cyst, showing histological features suggestive of eccrine duct origin, developing after a bee-sting. Br J Dermatol.2000;143(2):469-470.

[9]. LinkRE.Cutaneous Diseases of the External Genitalia. In: A. J. Wein, L. R. Kavoussi, A. C. Novick, A. W. Partin and C. A. Peters(Eds.), Campbell's Urology, 10th Edition, W. B. Saunders Co., Philadelphia.2012; 436- 467.

[10]. Chiu MY, Ho ST. Squamous cell carcinoma arising from an epidermal cyst. Hong Kong Med J.2007;13:482-484. 